\title{
Güneydoğu Anadolu Bölgesinin Hayvansal Atıklardan Elde Edilebilecek Enerji Potansiyeli
}

\author{
Fuat Lüle \\ Adıyaman Üniversitesi Teknoloji Fakültesi Enerji Sistemleri Mühendisliği Bölümü-Adıyaman \\ Sorumlu Yazar: flule@adiyaman.edu.tr \\ Geliş Tarihi: 21.06.2018
}

Kabul Tarihi: 23.10.2018

Öz

Bu çalı̧̧mada Güneydoğu Anadolu Bölgesi illerinin 2017 yılı büyükbaş, küçükbaş ve kanatlı hayvan potansiyeli ele alınmış ve elde edilebilecek enerji miktarı belirlenmiştir. Çalışmada İl Gıda Tarım ve Hayvancılık İl Müdürlükleri ve TUIKK verileri kullanılmıştır. Bu verilere göre 2017 yılında büyükbaş hayvan sayısı 1.464.441, küçükbaş hayvan sayısı 8.843.986 ve kanatlı hayvan sayıs1 7.312.847 olarak hesaplanmıştır. Bu hayvanlardan elde edilebilecek gübre miktarları ortalama olarak büyükbaş hayvanda 5.271 .988 ton/yll, küçükbaş hayvanda 6.190 .790 ton/y1l ve kanatlı hayvanda 160.883 ton/yıl, gübre miktarlarında hesaplanan biyogaz üretim miktarları sırasıyla $115.983,727,239.377,221$ ve $8.365,897 \mathrm{~m}^{3} / \mathrm{y}$ 1l olarak hesaplanmıștır. Bu verilerden elde edilebilecek toplam enerjinin eşdeğer karşıllı̆ı sırasıyla $1.962,445,4.050,263$ ve $141.551 \mathrm{GJ} / \mathrm{y} 1 \mathrm{l}$ olarak belirlenmiştir. Elde edilebilecek bu enerjinin küçük ve büyük ölçekli biyogaz tesisleri yapılarak bu enerjinin ekonomiye kazandırılması önem arz etmektedir.

Anahtar Kelimeler: Güneydoğu Anadolu Bölgesi, Biyogaz, Enerji, Hayvansal atık

\section{Potential Energy from Animal Wastes in the South-Eastern Anatolia Region Abstract}

In this study, the potential of cattle, small cattle and poultry in the South-Eastern Anatolia Region in 2017 was discussed and the amount of energy that could be obtained was determined. TUiK and Food Agriculture and Livestock data were used in the study. According to this data, the number of cattle in 2017 was 1.464.441 small cattle number of animals 8.843 .986 and the number of poultry was 7.312.847. The amount of fertilizer obtained from these animals was 5.271 .988 tons/year on average in cattle, 6.190 .790 tons/year in small cattle, 160.883 tons/year in poultry, $115.983 .727 \mathrm{~m}^{3} /$ year in large cattle, $239.377 .221 \mathrm{~m}^{3} /$ year in small cattle and $8.365 .897 \mathrm{~m}^{3} /$ year in winged cattle. The equivalent of the total energy obtained from these data was determined as $1.962 .445,4.050 .253$ and $141.551 \mathrm{GJ} /$ year, respectively. This energy can be obtained by making small and large-scale biogas facilities, it is important to gain this energy into the economy

Keywords: Southeastern Anatolia Region, Biogas, Energy, Animal waste

\section{Giriş}

Nüfusun 6 milyara yaklaştığı dünyamızda; ülkelerin sanayileşmesinin hızla artması, sosyal ve ekonomik kalkınmaların artması ve buna paralel olarak yaşam standartların yükselmesi sonucunda tüketimin artması dolayısıyla enerjiye olan talebi artırmaktadır. Hayatın her alanında ulaşım, sanayi, 1sınma vb. birçok alanda enerjiye ihtiyaç duyulmaktadır. Fosil enerji kaynakları bakımından oldukça fakir olan ve ithalatçı ülke konumunda olan Türkiye; 2015 yılında enerji ihtiyacının \%22,5'lik kısmını üretirken \%77,5'lik kısmını ithal ederek karşılamıştır. Enerji ithalatında doğalgazın \%99,5, petrolün \%97 ve taşkömürünün \%97'lik bölümü ithalat ile karşılanmıştır. Türkiye yenilenebilir enerji kaynakları bakımından oldukça zengin olmasına rağmen bu enerji kaynaklarını yeterli düzeyde değerlendiremediği görülmektedir. 2015 yılı yenilenebilir enerji kaynaklarımız Çizelge 1'de verilmiştir. Türkiye 2011 y1lında birincil enerji üretimi 32.228,9 BTEP (bin ton eşdeğer petrol) olarak gerçekleşmiştir. Birincil enerji üretiminin kaynaklar bazındaki dağılımı; ilk sırada \% 50 ile linyit olmak üzere, \%14 HES (Hidroelektrik santrali), odun (\%8), petrol (\%8), jeotermal-1S1 (\%5) ve taşkömürü (\%4) izlemektedir (Şekil 1), (Anonim 1, 2).

Doğanın kendi evrimi içinde, kullanılmasından sonra ki periyotun da aynen var olabilen enerji kaynağı olarak tanımlanan yenilenebilir enerji kaynakları olarak güneş, jeotermal, rüzgar, hidrolik vb. enerjilerin yanı sıra tarım ve orman atıkları ile katı atıklarda bu gruba girmektedir. Genelde Tarımsal 
ve katı atıklar yakma yöntemi kullanılarak bertaraf edilmektedir. Hayvansal atıklar; büyükbaş, küçükbaş ve kümes hayvanları yanı sıra at, eşek ve domuz gibi hayvanların gübreleri ile mezbaha artıkları ve hayvansal ürünlerin işlenmesi esnasında meydana gelen atıklar olarak tanımlanmaktadır (Koçer ve ark., 2006).

Çizelge 1. 2015 yılı Türkiye'nin Yenilenebilir enerji kaynakları potansiyeli (Anonim 3)

\begin{tabular}{ccl}
\hline Yenilenebilir Enerji Kaynakları & Potansiyel & Birim \\
\hline Güneş & 1500 & $\mathrm{kWh} / \mathrm{m}^{2} \mathrm{y} 1 \mathrm{l}$ \\
Hidrolik & 160,106 & $\mathrm{kWh} / \mathrm{y} 1$ \\
Rüzgar & 48,103 & $\mathrm{MW}$ \\
Jeotermal & 4,99 & $\mathrm{BTEB}$ \\
Biyokütle & 20 & $\mathrm{MTEP}$ \\
\hline
\end{tabular}

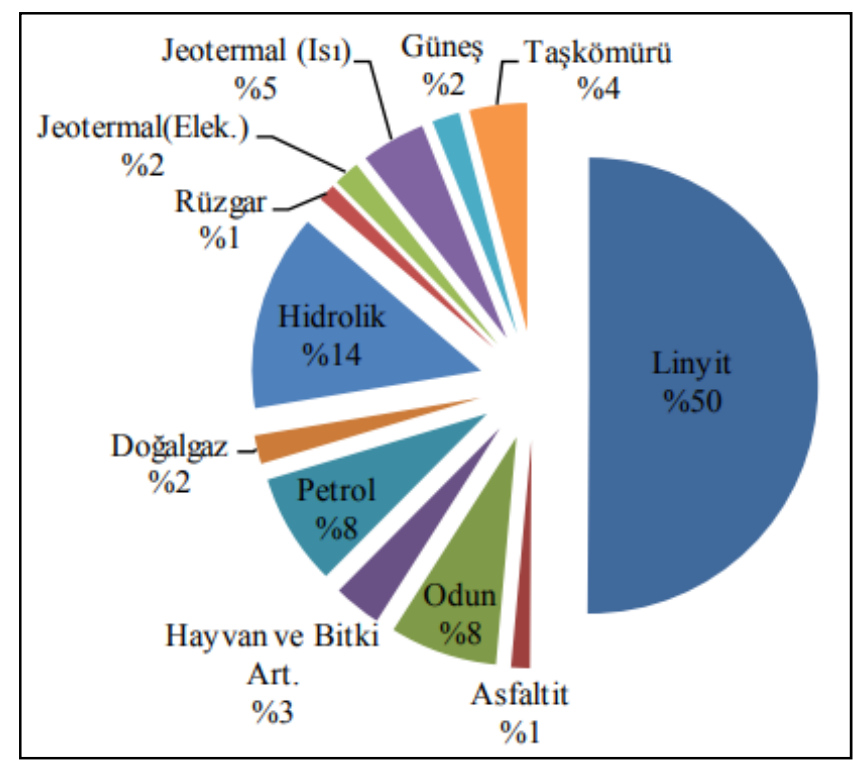

Şekil 1. 2011 yılı Türkiye'de birincil enerji üretiminin kaynaklar bazındaki dağılımı (Anonim 2, 3).

Çevre kirliliği ve temiz enerji üretimi bakımından organik madde içeren artıkların değerlendirilmesi oldukça önem taşımaktadır. Bu amaçla Başçetinçelik ve arkadaşlarının 2007 yılında yapmış oldukları çalışmada; gelişmekte olan ülkelerde kullanımı en yaygın olan kaynak biyokütle olduğunu bildirmişlerdir. Biyokütleden elde edilen enerjinin tüketimi Dünya genelinde yaklaşı \%15 iken gelişmekte olan ülkelerde bu oran $\% 43$ 'ü bulmaktadır.

Koçer ve Saatçi'nin 2007 yılında yapmış oldukları çalışmada; hayvancılık potansiyelinin ekonomik olarak önemli olduğu ülkemizde hayvansal atıklardan yararlanılarak, biyogaz üretim olanaklarının iyi bir şekilde saptanması gerektiğini bildirmişlerdir. Her yıl yakılmakta olan milyonlarca ton hayvansal atıklardan hem enerji hem de değeri artırılmış organik gübre biyogaz tesislerinden elde etmek mümkündür. Hayvancilık ile uğraşan çiftçilerin kurulacak biyogaz tesisleri ile hayvansal atıkların daha sağlıklı bir şekilde değerlendirilmesi sağlanacaktır. Elde edilebilecek bu enerjiyi yemek pişirmede, ısınmada, aydınlatmada gibi birçok kullanım alanlarında ekonomik bir şekilde değerlendirilmesini sağlanacağı belirtilmektedir. Gokdogan ve arkadaşlarının 2016 yılındaki çalışmasında özellikle kümes hayvancılığının son 15 yılın hayvancılıkta en yaygın olarak gelişen kolu haline geldiğini bildirmişlerdir.

Türkiye'nin; tarım, orman, hayvan, organik şehir atıklarından oluşan biyokütle potansiyeli 16,92 milyon TEP (Ton Eşdeğer Petrol) olarak hesaplanmıştır. Ancak yararlanma oranı henüz istenilen seviyeye ulaşmamıştır; 1989 yılında \%15,2 iken 1994'de y1lında \%12.4 oranında kalmıştır. 2001 yılında ise kullanılan biyokütle enerjisi sadece 6,98 milyon TEP düzeylerindedir (Anonim 4; Yokuş ve Avcioğlu, 2012). 
Türkiye'nin biyokütle potansiyelinin yaklaşık \%60'1 değerlendirildiği varsayıldığında bu potansiyel $300 \mathrm{MW}$ güce sahip bir enerji tesisine eşdeğerdir. $1330 \mathrm{MW}$ kurulu güce sahip Keban hidro elektrik santralinden (HES) her 4.5 yılda bir ürettiği enerji kadar enerji elde edilmesi mümkün olacaktır (Ersoy, 2007).

Güç ve Yılmaz'ın 2008 yılındaki çalışmasında; biyogaz tesislerinin birçok avantajı bulunmaktadır. Elde edilecek enerjinin yakıt olarak kullanılması yanı sıra arta kalan organik maddenin gübre olarak kullanılması durumunda ürün verimliliğinde ciddi artışlar söz konusu olacaktır. Biyogaz üretiminin çevreye olan katkısı da göz ardı edilmemelidir. Fermantasyon sırasında zararlı birçok organizma yok olmaktadır ve gübre kokusu kalkmaktadır.

\section{Materyal ve Yöntem}

Bu Çalışmada; Gaziantep, Adıyaman, Şanlıurfa, Siirt, Mardin, Batman, Diyarbakır, Şırnak ve Kilis illerinden oluşan Güneydoğu Anadolu Bölgesinin TUİK verilerinden yararlanılmıştır. 2017 yılı büyükbaş (Bu grubu dana, buzağı, tosun, düve, inek boğa, öküz, sığır ve manda oluşturmaktadır), küçükbaş (Bu grubu koyun ve keçi oluşturmaktadır) ve kanatlı hayvan (Bu grubu tavuk, hindi ördek ve kaz oluşturmaktadır) potansiyeli ele alınmış ve elde edilebilecek enerji miktarı belirlenerek Güneydoğu Anadolu Bölgesinde hayvansal atıklarından elde edilebilecek gübre miktarlarının biyogaz olarak değerlendirilmesi durumda elde edilebilecek enerjinin çalışması yapılmıştır.

Akbulut ve Dikici'ye göre (Akbulut ve Dikici, 2004), "Biyogaz potansiyelini belirlemek için aşağıdaki kabuller ve araştırma sonuçları kullanılmıştır" (Deniz, 1987, Baran ve ark. 2017).

Gübre ile ilgili kabuller; Büyükbaş hayvandan 3,6 ton/(yıl.gübre), küçükbaş hayvandan 0,7 ton/(y1l.gübre), kanatlı hayvandan 0,022 ton/y1l gübre ortalama olarak elde edildiği kabul edilir. Gübrelerin yaklaşık 1/3'ünün meralarda kaybolduğu dikkate alınmıştır.

Biyogaz ile ilgili kabuller; 1 ton büyükbaş hayvan gübresinden $33 \mathrm{~m}^{3}$ biyogaz, 1 ton küçükbaş hayvan gübresinden $58 \mathrm{~m}^{3}$ biyogaz, 1 ton kanatlı hayvan gübresinden $78 \mathrm{~m}^{3}$ biyogaz elde edildiği dikkate alınmıştır.

Biyogazın elektrik enerjisi olarak eşdeğeri; Akbulut ve Dikici’ye göre (Akbulut ve Dikici, 2004), " $1 \mathrm{~m}^{3}$ biyogazın elektrik enerjisi cinsinden değeri; $4.70 \mathrm{kWh}$ enerjidir (Bilir ve ark., 1983). Bu kabuller, araştırma sonuçları ve verilere göre Güneydoğu Anadolu bölgesinde 2017 yılı büyükbaş, küçükbaş ve kanatlı hayvan sayısına göre gübre, biyogaz ve enerji potansiyeli hesabı yapılmıştır

$1 \mathrm{~m}^{3}$ biyogazın sağladığı 1S1 miktarı $5000 \mathrm{kcal}$ olup diğer yakıtlara oranla eşdeğerleri çizelge 2'de verilmiştir;

Çizelge $2.1 \mathrm{~m}^{3}$ biyogazın diğer yakıtlara olan eşdeğerleri (Yaldız, 2004; Gülşen ve Çiftçi, 2017)

\begin{tabular}{lll} 
& Yakıt türü & Birim \\
\cline { 2 - 3 } $1 \mathrm{~m}^{3}$ biyogaz & Gaz yă̆ 1 & 0,63 litre \\
& Odun & $3,47 \mathrm{~kg}$ \\
& Kömür & $1,46 \mathrm{~kg}$ \\
Bütan gazı & $0,43 \mathrm{~kg}$ \\
& Elektrik & $4,7 \mathrm{kWh}$ \\
& Benzin & 0,8 litre \\
\hline
\end{tabular}

\section{Bulgular ve Tartıșma}

Güneydoğu Anadolu bölgesinde bulunan illerin 2017 yılı büyükbaş hayvan sayısı 1.464,441, küçükbaş hayvan sayısı $8.843,986$ ve kanatlı hayvan sayıs1 7.312 .847 olarak hesaplanmıştır. İller bazında 2017 yılı ortalama büyükbaş, küçükbaş ve kanatlı hayvan sayısı, Çizelge 3'de, Çizelge 4'te elde edilebilecek biyogaz ve elektrik üretimi, Çizelge 5'te elde edilebilecek enerjinin MJ ve GJ cinsinden eşdeğeri verilmiştir.

Çizelge 3. 2017 yılı GDA bölgesi illeri büyükbaş, küçükbaş ve kanatlı hayvan sayısı

Iller




\begin{tabular}{llll} 
Adiyaman & 117.380 & 320.507 & 284.474 \\
Batman & 85.776 & 811.749 & 119.756 \\
Diyarbakır & 538.980 & 1.805 .644 & 781.494 \\
Gaziantep & 191.842 & 612.906 & 3.939 .811 \\
Kilis & 8.886 & 197.114 & 260.620 \\
Mardin & 118.302 & 966.765 & 966.765 \\
Siirt & 28.147 & 1.123 .116 & 113.065 \\
Sanliurfa & 321.940 & 1.969 .120 & 717.755 \\
Sirnak & 53.188 & 1.037 .065 & 129.107 \\
\hline
\end{tabular}

Çizelge 4. 2017 yılı GDA Bölgesi illerinde büyükbaş, küçükbaş ve kanatlı hayvanlardan elde edilebilecek biyogaz ve elektrik üretimi

Çizelge 5. 2017 yılı GDA Bölgesi illerinde büyükbaş, küçükbaş ve kanatlı hayvanlardan elde edilebilecek enerjinin MJ ve GJ cinsinden eşdeğeri

\begin{tabular}{ccccccc}
\hline \multirow{2}{*}{ Y11 } & \multicolumn{2}{c}{ Büyükbaş hayvan. } & \multicolumn{2}{c}{ Küçükbaş hayvan } & \multicolumn{2}{c}{ Kanatlı hayvan } \\
\cline { 2 - 7 } & MJ & GJ & MJ & GJ & MJ & GJ \\
\hline 2017 & 1.962 .444 .664 & 1.962 .445 & 4.050 .262 .580 & 4.050 .263 & 141.550 .977 & 141.551 \\
\hline
\end{tabular}

Güneydoğu Anadolu Bölgesinde Şekil 6, 7 ve 8 'de verilmiştir. Çizelge 6, 7 ve 8 incelendiğinde büyükbaş hayvan atıklarından elde edilebilecek biyogaz; Diyarbakır ili 23.283.936 $\mathrm{m}^{3} / \mathrm{y} 1 \mathrm{l}$ ile ilk sırada yer alırken Kilis $383.875 \mathrm{~m}^{3} / \mathrm{y} 1 \mathrm{l}$ ile son sırada bulunmaktadır. Küçükbaş hayvanlardan elde edilebilecek biyogaz $54.216 .437 \mathrm{~m}^{3} / \mathrm{y} 1 \mathrm{l}$ ile Şanlıurfa ilk sırada yer almaktadır. Kilis ili $5.427 .205 \mathrm{~m}^{3} / \mathrm{y} 1 \mathrm{l}$ ile son sırada yer almaktadır. Kanatlı hayvanlardan elde edilebilecek biyogaz ise $4.507 .144 \mathrm{~m}^{3} / \mathrm{y} 1 \mathrm{l}$ ile Gaziantep, $129.346 \mathrm{~m}^{3} / \mathrm{y} 1 \mathrm{l}$ ile Siirt sonuncu sirada yer almaktadır.

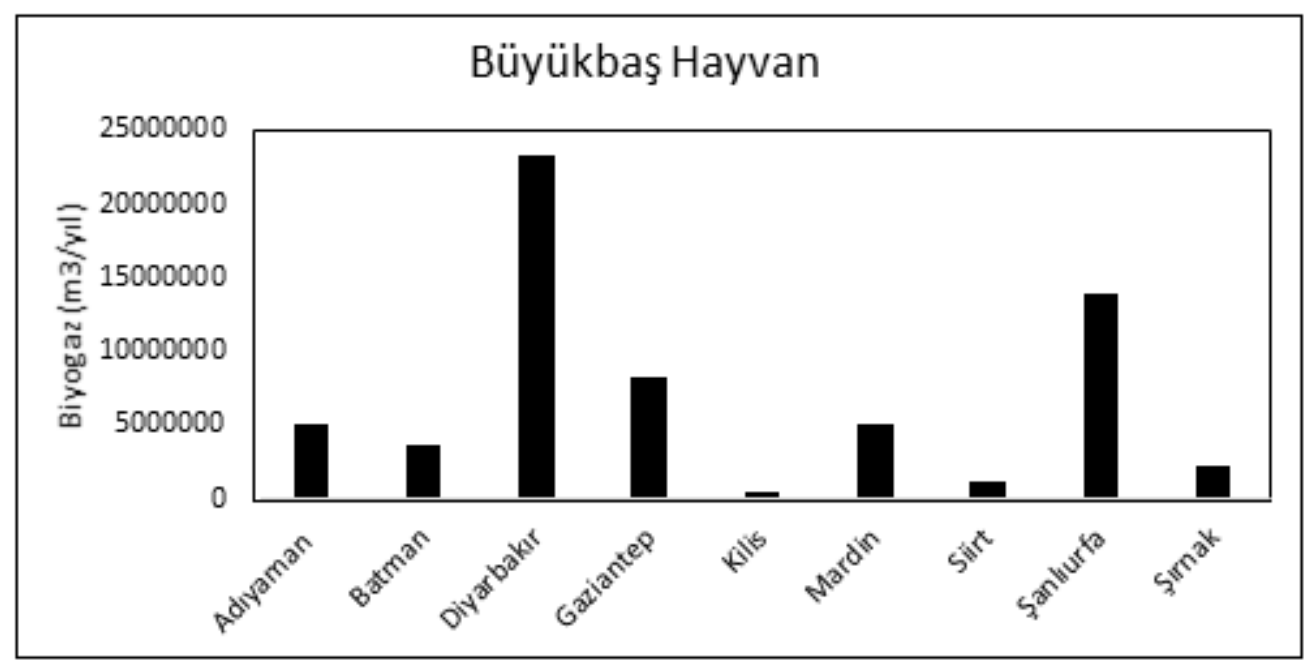

Şekil 6. Güneydoğu Anadolu Bölgesinde bulunan illerin büyükbaş hayvan atıklarından elde edilebilecek biyogaz $\left(\mathrm{m}^{3} / \mathrm{y} 1\right)$ miktarları 


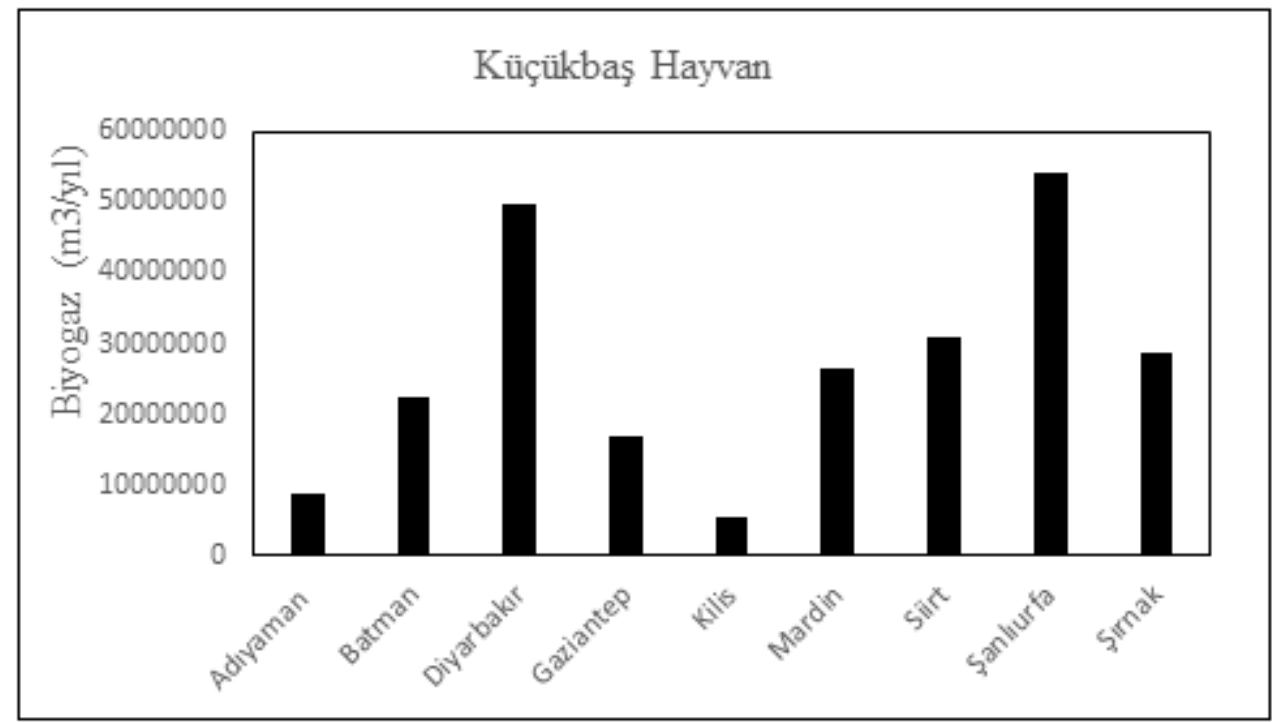

Şekil 7. Güneydoğu Anadolu Bölgesinde bulunan illerin küçükbaş hayvan atıklarından elde edilebilecek biyogaz $\left(\mathrm{m}^{3} / \mathrm{y} 1\right)$ miktarları

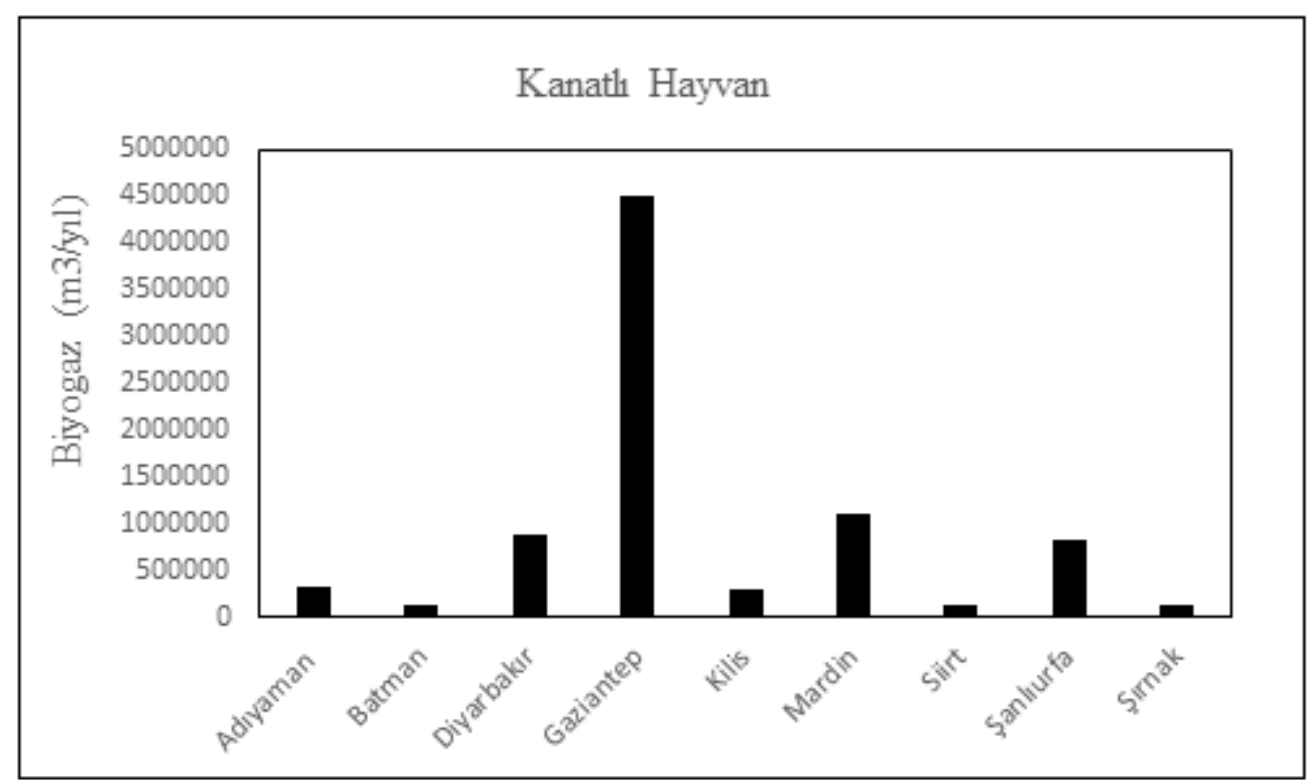

Şekil 8. Güneydoğu Anadolu Bölgesinde bulunan illerin kanatlı hayvan atıklarından elde edilebilecek biyogaz $\left(\mathrm{m}^{3} / \mathrm{y} 1 \mathrm{l}\right)$ miktarları

\section{Sonuç ve Öneriler}

Yapılan bu çalışmada Güneydoğu Anadolu Bölgesinde bulunan illerin hayvansal atıkların değerlendirilmesi konusunda biyogaz potansiyeli belirlenmeye çalışılmıştır. Özellikle Güneydoğu Anadolu Bölgesinde hayvansal atıklar tezek yapılarak yakma yöntemiyle değerlendirilmektedir. Yeni ve yenilenebilir enerji kaynaklarından olan biyogazın, biyogaz tesisleri kurularak temiz enerji elde edilerek ekonomiye kazanılması kırsal kesimde yaşayan hem yöre insanı hem de ülke ekonomisine katk1 ve yarar sağlayacağı kaçınılmazdır. Kırsal alanda yaşayan ve hayvancılıkla geçimini sağlayan çiftçilere ve işletmelere biyogaz tesisleri ve bu tesisin çıktıları ayrıntılı olarak verilmelidir. biyogaz tesisleri kurularak atıkların açık alanda ya da depolama alanlarında çürümesi ile oluşan metan, karbondioksit ve hidrojen sülfür gibi birçok kirletici gazların ve kötü kokunun atmosfere verilmesi önlenebilmektedir. Kurulacak olan biyogaz tesislerinden çıkan fermente olmuş organik gübrenin daha verimli bir gübre olarak tarıma katkı sağlayacağı bunun yanı sıra kullanılmakta olan kimyasal gübrenin azaltılması bakımından önemli yararlar sağlayacağı çok açıktır. Bu enerjinin kazanılmasında küçük ve büyük ölçekli işletme girişimcilerin desteklenmesi sağlanmalıdır. 


\section{Kaynaklar}

Akbulut, A., Dikici, A., 2004. Elazı̆̆ İli’nin biyogaz potansiyeli ve maliyet analizi. Doğu Anadolu Bölgesi Araştırmaları Dergisi. 2(2): 36-41.

Anonim 1. http://www1.mmo.org.tr/resimler/ dosya_ekler/a8c16d2696b35f9_ek.pdf) Erişim: 25.02.2018

Anonim 2. http://enerjienstitusu.com/2011/07/ 11/dunya-genelinde-enerji-tuketimi-patladi/. Erişim: 25.02.2018

Anonim 3. http://www.enerji.gov.tr/File/?path=ROOT\%2f1\%2fDocuments\%2fSekt\%C3\%B6r\%20Raporu \%2fEUAS-Sektor_Raporu2016.pdf Erişim: 25.02.2018

Anonim 4. Yenilenebilir enerji raporu, Karacadağ Kalkınma Ajansı, 2010, http://eng.harran.edu.tr/ aktacir/Karacadag_Rapor_07032011.pdf, Erişim: 21.02.2018

Baran, M.F., Lule, F., Gökdoğan, O., 2017. Adıyaman îlinin hayvansal atıklardan elde edilebilecek enerji potansiyeli. Türk Tarım ve Doğa Bilimleri Dergisi. 4 (3):245-249.

Başcetinçelik, A., Öztürk, H., Karaca, C., 2007.Türkiye'de tarımsal biyokütleden enerji üretimi olanakları. IV. Yeni ve Yenilenebilir Enerji Kaynakları Sempozyumu, Kayseri.

Bilir, M., Deniz, Y., Karabay, E., 1983. Biyogaz üretimine yönelik değerlerin saptanması. Toprak Su Araştırma Ana Projesi, Proje No: 872, Ankara.

Ersoy, Y., 2007. İzmir Evsel Çöpünden Biyometan Şeklinde Enerji Geri Kazanılabilirliği. Ege Üniversitesi Fen Bilimleri Enstitüsü Çevre Bilimleri Anabilim Dalı, Yüksek Lisans Tezi, İzmir

Deniz, Y., 1987. Türkiye'de Biyogaz Potansiyeli ve Biyogazın Sağlayacağı Yararlar. Tarım Orman ve Köy İşleri Bakanlığı Köy Hizmetleri Genel Müdürlüğ̈̈ Ankara Araştırma Enstitüsü Müdürlüğü Yayınları. No:48.

Güç, M., Yılmaz, V., 2008. Organik atıklardan kaynaklı sera gazları salınımlarının azaltılmasında anerobik bozundurmanın önemi. VII Ulusal Ulusal Temiz Enerji Sempozyumu, s 139-150, İstanbul

Gokdogan, O., Ayasan, T., Inci, H., Sogut, B., Sengul, T., 2016. Effect of different housing systems (cages versus floor) on energy efficiency analysis of meat type Japanese quails. Indian Journal of Animal Sciences. 86 (9): 1051-1054.

Gülşen, H., Çiftçi, C., 2017. Güneydoğu anadolu bölgesi’nin yenilenebilir enerji kaynakları bakımından potansiyelinin araştırılması. Akademi Mühendislik ve Fen Bilimleri Dergisi. 1 (3): 48-56.

Koçer, N.N., Öner, C., Sugözü, İ., 2006. Türkiye'de hayvancıllk potansiyeli ve biyogaz üretimi. Doğu Anadolu Bölgesi Araştırmaları.

Koçer, N.N., Saatçi, Y., 2007. Elazığ'daki hayvansal atıkların biyoenerji potansiyeli. Doğu Anadolu Bölgesi Araștırmaları. 119-124.

Yaldız, O., 2004. Biyogaz teknolojisi. Ders Kitabı, Akdeniz Üniversitesi Yayınları. Yayın No: 78, 181s., Antalya.

Yokuş, İ., Avcıŏglu, A.O., 2012. Sivas ilindeki hayvansal atıklardan biyogaz potansiyelinin belirlenmesi. 27.Tarımsal Mekanizasyon Ulusal Kongresi, 5-7 Eylül 2012, Samsun 